Check for updates

Cite this: RSC Adv., 2018, 8, 8552

\title{
Novolac-based poly(1,2,3-triazolium)s with good ionic conductivity and enhanced $\mathrm{CO}_{2}$ permeation $\dagger$
}

\author{
Lvyuan Ye, (D) Liqiang Wan, (D) Junkun Tang, (D) Yujing Li and Farong Huang (D) *
}

Novolac-based poly(1,2,3-triazolium)s with 1,2,3-triazolium side groups spaced by oligo(ethylene glycol), a new kind of poly(ionic liquid) membrane, was prepared via the well-known Click chemistry (1,3-dipolar cycloaddition reaction). The thermal properties, ionic conductivity and gas permeation performance of these self-standing membranes were investigated. The obtained membranes exhibit glass transition temperatures ranging from $-1{ }^{\circ} \mathrm{C}$ to $-7.5^{\circ} \mathrm{C}$, and a temperature at $10 \%$ weight loss above $330{ }^{\circ} \mathrm{C}$. These membranes have good ionic conductivity $\left(\sigma_{\mathrm{DC}}\right.$ up to $5.1 \times 10^{-7} \mathrm{~s} \mathrm{~cm}^{-1}$ at $30{ }^{\circ} \mathrm{C}$ under anhydrous conditions) as compared with the reported 1,2,3-triazolium-based crosslinked polymers. And they could be potentially used for $\mathrm{CO}_{2}$ separation as they exhibit enhanced $\mathrm{CO}_{2}$ permeability up to 434.5 barrer at 4 atm pressure.

Received 18th January 2018

Accepted 13th February 2018

DOI: 10.1039/c8ra00541a

rsc.li/rsc-advances main-chain TPILs with bis(trifluoromethylsulfonyl)imide $\left(\mathrm{TFSI}^{-}\right.$) anions have shown relatively high ionic conductivity $\left(2.0 \times 10^{-5} \mathrm{~S} \mathrm{~cm}^{-1}\right)$ with a low glass transition temperature $\left(T_{\mathrm{g}}\right)$ of $-35{ }^{\circ} \mathrm{C}^{\mathbf{1 0}}$ Hyperbranched TPILs with oligo(ethylene glycol) (OEG) terminal groups exhibited ionic conductivity $7.7 \times$ $10^{-6} \mathrm{~S} \mathrm{~cm}^{-1}$ with $T_{\mathrm{g}}$ of $-14.9^{\circ} \mathrm{C}^{.11}$ Several side-chain TPILs were also investigated, for instance, poly(vinyl ester 1,2,3-triazolium) with $\mathrm{TFSI}^{-}$anions displayed ionic conductivity of $9.2 \times$ $10^{-7} \mathrm{~S} \mathrm{~cm}^{-1}$ with $T_{\mathrm{g}}$ of $-16{ }^{\circ} \mathrm{C}$ while polyacrylates with $1,2,3-$ triazolium side groups spaced by TEG groups displayed higher ionic conductivity of $1.1 \times 10^{-5} \mathrm{~S} \mathrm{~cm}^{-1}$ with lower $T_{\mathrm{g}}$ of $-36{ }^{\circ} \mathrm{C.}^{12,13}$ It can be concluded that the $\mathrm{TFSI}^{-}$is the best candidate anion for conductive materials, meanwhile, the introduction of 1,2,3-triazolium in the side groups spaced by rich ether groups are effective ways to improve the ionic conductivity of the obtained TPILs. Unfortunately, some of the previously reported TPILs were unable to be used as gas separation membranes due to their brittle or viscous nature resulting from the flexible polymer structure.

To promote innovative applications in diverse fields, 1,2,3triazolium-based crosslinked polymers are emerging. ${ }^{\mathbf{1 4 , 1 5}}$ For example, 1,2,3-triazolium-based epoxy-amine networks and polyether-based 1,2,3-triazoliums were recently reported and both of them show satisfying ionic conductivity (up to $2.0 \times$ $10^{-7} \mathrm{~S} \mathrm{~cm}^{-1}, 10^{-6} \mathrm{~S} \mathrm{~cm}^{-1}$, separately). ${ }^{9,16}$ However, only the latter have been evaluated as gas separation membranes, for the first time. In view of the fact that innovation and breakthrough is still in need in both the crosslinked TPILs and their applications in $\mathrm{CO}_{2}$ separation fields, we attempt to design and prepare new selfstanding crosslinked TPILs membranes by introducing rigid benzene rings and 1,2,3-triazoles in the polymer structure.

In this contribution, we report novolac-based poly(1,2,3triazolium)s (NPTAm) membranes with novolac-based
Key Laboratory of Specially Functional Polymeric Materials and Related Technology, School of Materials Science and Engineering, East China University of Science and Technology, Ministry of Education, Shanghai 200237, China. E-mail: fhuanglab@ ecust.edu.cn; Tel: +86-021-64251110

$\dagger$ Electronic supplementary information (ESI) available. See DOI: 10.1039/c8ra00541a 
poly(1,2,3-triazole)s as backbone, together with 1,2,3-triazolium in side groups spaced by OEG, containing TFSI $^{-}$as counteranion. Thermal, ion-conducting properties and $\mathrm{CO}_{2}$ permeability of these membranes were investigated.

\section{Experimental}

\section{Materials}

PN resin, $p$-xylyene diazide and azido-2-(2-(2-methoxyethoxy) ethoxy)ethane (OEG- $\mathrm{N}_{3}$ ) were prepared according to the literature, separately. ${ }^{17-19}$ Sodium ascorbate $(99 \%)$ and $\mathrm{CuSO}_{4} \cdot 5 \mathrm{H}_{2} \mathrm{O}$ (99\%) were purchased from Shanghai Chemical Reagents Company. Iodomethane $\left(\mathrm{CH}_{3} \mathrm{I}, 99 \%\right)$ was purchased from Shanghai Dibo Chemical Reagents Company. Ethylenediaminetetraacetic acid disodium salt (EDTA), lithium bis(trifluoromethanesulfonyl)imide (LiTFSI), and other reagents and solvents were purchased from Adamas and used as received.

\section{Synthesis of PN-OEG through CuAAC}

To a solution of PN resin (3.17 g, $20 \mathrm{mmol}$ of alkyne group) and OEG-N $\mathrm{N}_{3}(1.39 \mathrm{~g}, 8 \mathrm{mmol})$ in DMF $(50 \mathrm{~mL}), \mathrm{CuSO}_{4} \cdot 5 \mathrm{H}_{2} \mathrm{O}$ aqueous solution $\left(0.8 \mathrm{mmol}\right.$ in $1.2 \mathrm{~mL}$ of $\left.\mathrm{H}_{2} \mathrm{O}\right)$ was added. After bubbling nitrogen for $30 \mathrm{~min}$, fresh sodium ascorbate solution $(2.4 \mathrm{mmol}$ in $0.8 \mathrm{~mL} \mathrm{H}_{2} \mathrm{O}$ ) was added. The resulting mixture was stirred for $48 \mathrm{~h}$ at $55{ }^{\circ} \mathrm{C}$. After evaporation of the solvent under reduced pressure, the mixture was poured into $\mathrm{H}_{2} \mathrm{O}$, then extracted with DCM $(50 \mathrm{~mL})$, and the organic layer was washed with EDTA aqueous solution and saturated $\mathrm{NaCl}$ aqueous solution until the aqueous phase became colourless. After dried by $\mathrm{MgSO}_{4}$, the organic layer was concentrated and precipitated three times with diethyl ether, then dried in vacuum and a reddish brown solid PN-OEG (3.88 g, yield 85\%) was obtained. ${ }^{1} \mathrm{H}$ NMR (400 MHz, DMSO, ppm): $\delta$ 8.11-7.94 (m, triazole- $H)$, 7.08-6.70 $(\mathrm{m}$, aromatic- $H$ ), $5.02\left(\mathrm{~s},-\mathrm{N}-\mathrm{N}=\mathrm{NCH}_{2} \mathrm{CH}_{2} \mathrm{O}-\right), 4.71\left(\mathrm{~s},-\mathrm{O}-\mathrm{CH}_{2}-\right.$ $\mathrm{C} \equiv \mathrm{C}-), 4.48\left(\mathrm{~s},-\mathrm{C}-\mathrm{CH}_{2}-\mathrm{C}, \quad-\mathrm{N}=\mathrm{N}-\mathrm{NCH}_{2} \mathrm{CH}_{2}-\mathrm{O}-, \quad-\mathrm{N}=\mathrm{N}-\right.$ $\left.\mathrm{NCH}_{2} \mathrm{CH}_{2}-\mathrm{O}-\right), 3.71$ (m, $\left.-\mathrm{CH}_{2} \mathrm{O}^{-}\right), 3.37$ (s, $\left.-\mathrm{C} \equiv \mathrm{CH}\right), 1.00$ (s, $-\mathrm{CH}_{2} \mathrm{CH}_{3}$ ).

\section{Synthesis of [PN-OEG] $]^{+} \mathbf{I}^{-}$}

To a solution of PN-OEG ( $1.71 \mathrm{~g}, 3 \mathrm{mmol}$ of triazole groups) in $50 \mathrm{~mL} \mathrm{CH} \mathrm{CH}_{3} \mathrm{CH}_{3} \mathrm{I}(1.42 \mathrm{~g}, 10 \mathrm{mmol})$ was added, and the mixture was stirred at $45{ }^{\circ} \mathrm{C}$ for $3 \mathrm{~d}$. The mixture was concentrated and precipitated three times in diethyl ether and dried in vacuum to get [PN-OEG] $]^{+} \mathbf{I}^{-}(2.03 \mathrm{~g}$, yield $95 \%)$ as a yellow solid. ${ }^{1} \mathrm{H}$ NMR (400 MHz, DMSO, ppm): $\delta 9.01$ (s, triazolium- $H$ ), 7.08$6.70(\mathrm{~m}$, aromatic- $H), 5.44\left(\mathrm{~s},-\mathrm{N}-\mathrm{N}=\mathrm{NCH}_{2} \mathrm{CH}_{2} \mathrm{O}-\right)$, 4.86-4.71 $\left(\mathrm{m},-\mathrm{O}-\mathrm{CH}_{2}-\mathrm{C} \equiv \mathrm{C}-\right)$, 4.35 (m, $\left.-\mathrm{NCH}_{3}\right), 4.16$ (s, $\left.-\mathrm{CCH}_{2} \mathrm{C}-\right)$, 3.93 $\left(\mathrm{m},-\mathrm{N}=\mathrm{N}-\mathrm{NCH}_{2} \mathrm{CH}_{2} \mathrm{O}-, \quad-\mathrm{N}=\mathrm{N}-\mathrm{NCH}_{2} \mathrm{CH}_{2}-\mathrm{O}-\right), 3.55 \quad(\mathrm{~m}$, $\left.-\mathrm{CH}_{2} \mathrm{O}-\right), 3.37$ (s, $\left.-\mathrm{C} \equiv \mathrm{CH}\right), 1.00\left(\mathrm{~s},-\mathrm{CH}_{2} \mathrm{CH}_{3}\right)$.

\section{Synthesis of [PN-OEG $]^{+}$TFSI $^{-}$}

A solution of [PN-OEG] $]^{+} \mathbf{I}^{-}(1.78 \mathrm{~g}, 2.5 \mathrm{mmol}$ of 1,2,3-triazole groups) and LiTFSI (2.15 g, $7.5 \mathrm{mmol})$ in a mixture of acetone $(35 \mathrm{~mL})$ and methanol $(35 \mathrm{~mL})$ was stirred at $45{ }^{\circ} \mathrm{C}$ for $2 \mathrm{~d}$. The heterogeneous mixture was concentrated and precipitated in deionized water several times, until no AgI precipitate generated when the deionized water was tested with $\mathrm{AgNO}_{3}$, then dried in vacuum, and a reddish brown viscous material [PNOEG $^{+}$TFSI $^{-}$(1.30 g, yield $60 \%$ ) was obtained. ${ }^{1} \mathrm{H}$ NMR (400 MHz, DMSO, ppm): $\delta 8.95$ (s, triazolium- $H$ ), 7.00-6.84 (m, aromatic- $H$ ), $5.36\left(\mathrm{~s},-\mathrm{N}-\mathrm{N}=\mathrm{NCH}_{2} \mathrm{CH}_{2} \mathrm{O}-\right), 4.83\left(\mathrm{~m},-\mathrm{O}-\mathrm{CH}_{2}-\right.$ $\mathrm{C} \equiv \mathrm{C}-), 4.31\left(\mathrm{~s},-\mathrm{NCH}_{3}\right), 3.91\left(\mathrm{~m},-\mathrm{CCH}_{2} \mathrm{C}-,-\mathrm{N}=\mathrm{N}-\mathrm{NCH}_{2} \mathrm{CH}_{2}-\right.$ $\left.\mathrm{O}-,-\mathrm{N}=\mathrm{N}-\mathrm{NCH}_{2} \mathrm{CH}_{2}-\mathrm{O}-\right) 3.56\left(\mathrm{~m},-\mathrm{CH}_{2} \mathrm{O}-\right), 3.37(\mathrm{~s},-\mathrm{C} \equiv \mathrm{CH})$, $1.00\left(\mathrm{~s},-\mathrm{CH}_{2} \mathrm{CH}_{3}\right) .{ }^{19} \mathrm{~F}$ NMR (400 MHz, DMSO, ppm): $\delta-78.8$.

\section{Preparation of the crosslinked NPTAm membrane}

A stoichiometric mixture of [PN-OEG] ${ }^{+}$TFSI $^{-}(1.15 \mathrm{~g}, 2 \mathrm{mmol}$ of alkyne) and $p$-xylyene diazide $(0.19 \mathrm{~g}, 1 \mathrm{mmol})$ was dissolved in DMF ( $5 \mathrm{~g}$ ), and then was stirred at $70{ }^{\circ} \mathrm{C}$ for $2 \mathrm{~h}$, following by casting the concentrated mixture onto a glass plate and levelling it with a stainless steel scraper, which had been preheated to $70{ }^{\circ} \mathrm{C}$. The glass plate was placed onto a horizontal platform. Then, the system was sequentially cured $\left(70{ }^{\circ} \mathrm{C} / 3 \mathrm{~h}+80^{\circ} \mathrm{C} / 3 \mathrm{~h}+\right.$ $120^{\circ} \mathrm{C} / 2 \mathrm{~h}+150{ }^{\circ} \mathrm{C} / 4 \mathrm{~h}$ ). After that, the heating oven was turned off and the whole system was gradually cooled to room temperature. The membrane, named as NPTAm-1, was obtained by immersing the glass plate in water and was then dried at $100{ }^{\circ} \mathrm{C}$ for $0.5 \mathrm{~h}$ for further use.

By changing the feed molar ratio of PN with OEG-N $\mathrm{N}_{3}(1: 0.6$ and $1: 0.8$ ) when initially synthesizing PN-OEG, NPTAm-2 and NPTAm-3 membranes were separately obtained (ESI $\dagger$ ).

\section{Characterization}

Spectroscopic and thermal characterizations. All NMR spectra data were obtained on a Bruker Advance $400 \mathrm{MHz}$ Spectrometer (Bruker, USA) using tetramethylsilane (TMS) as an internal standard in DMSO- $d_{6}$. FT-IR spectrum measurements were carried out on a Nicolet iS10 FTIR spectrophotometer (Thermo Scientific, USA) in the region of 4000-400 $\mathrm{cm}^{-1}$ using $\mathrm{KBr}$ pellets. TGA were conducted on a TGA/DSC 1 (Mettler Toledo, Switzerland) under nitrogen at a heating rate of $10{ }^{\circ} \mathrm{C} \min ^{-1}$. DSC was performed in a nitrogen atmosphere on a TA Q2000 analyser (TA, USA). The samples were first heated from $40{ }^{\circ} \mathrm{C}$ to $150{ }^{\circ} \mathrm{C}$ and held at $150{ }^{\circ} \mathrm{C}$ for $2 \mathrm{~min}$ to eliminate the thermal history, then cooled to $-30{ }^{\circ} \mathrm{C}$, and finally heated again from $-30{ }^{\circ} \mathrm{C}$ to $150{ }^{\circ} \mathrm{C}$. The heating or cooling rate remained $20{ }^{\circ} \mathrm{C} \mathrm{min}^{-1}$ and $T_{\mathrm{g}}$ values were recorded during the second heating cycle.

Ionic conductivity measurements. The ionic conductivity was measured using a high-resolution Alpha-Analyzer (BDS, Novocontrol GmbH, Germany) assisted by a Quatro temperature controller under nitrogen. The samples were placed between two polished brass electrodes and heated at $110^{\circ} \mathrm{C}$ for $4 \mathrm{~h}$ under a flow of pure nitrogen. At the same time, the dielectric properties were measured to monitor the equilibration process of the sample. Frequency sweeps were then performed isothermally from $10 \mathrm{MHz}$ to $0.1 \mathrm{~Hz}$ by applying a sinusoidal voltage of $0.1 \mathrm{~V}$ ranging from $110{ }^{\circ} \mathrm{C}$ to $-30{ }^{\circ} \mathrm{C}$ in steps of $20^{\circ} \mathrm{C}$. The temperature was controlled by heating the sample under a flow of pure nitrogen, which could exclude oxygen and humidity in the test chamber. 
Gas permeation measurements. The gas permeation properties of the membranes were measured by a standard variable volume method at upstream gas pressure of 4 atm pressure at $25{ }^{\circ} \mathrm{C}$ according to the literature ${ }^{20}$ (Fig. S1 $\dagger$ ).

The gas permeability $(P)$ was determined from eqn (1):

$$
P=\frac{q L}{A t \Delta p}
$$

where $q$ is the infiltration capacity of the gas passing through the membrane, $L$ is the membrane thickness, $\Delta p$ is the differential pressure of feed and permeate side and $A$ is the effective membrane area.

The $\mathrm{CO}_{2} / \mathrm{N}_{2}$ selectivity $\left(\alpha_{\mathrm{CO}_{2} / \mathrm{N}_{2}}\right)$ was calculated from eqn (2):

$$
\alpha_{\mathrm{CO}_{2} / \mathrm{N}_{2}}=\frac{P_{\mathrm{CO}_{2}}}{P_{\mathrm{N}_{2}}}
$$

where $P_{\mathrm{CO}_{2}}$ is the gas permeability of $\mathrm{CO}_{2}$ and $P_{\mathrm{N}_{2}}$ is the gas permeability of $\mathrm{N}_{2}$. The data averaged from 3 samples for each membrane.

\section{Results and discussion}

\section{Preparation of NPTAm membranes through CuAAC reaction and 1,3-dipolar cycloaddition}

As shown in Fig. 1, PN-OEG was firstly obtained through $\mathrm{Cu}(\mathrm{I})$ catalyzed azide-alkyne cycloaddition reaction (Click chemistry) by adding the catalyst of $\mathrm{CuSO}_{4} / \mathrm{NaVc}$ to the solution of $\mathrm{PN}$ and OEG-N $\mathrm{N}_{3}$ in DMF. Next, PN-OEG was alkylated by $\mathrm{CH}_{3} \mathrm{I}$ to get the triazolium iodide polymers, [PN-OEG $]^{+} \mathbf{I}^{-}$, following an anion metathesis reaction performed by exchanging the iodide anion $\left(\mathrm{I}^{-}\right)$with TFSI $^{-}$. After being washed through precipitating the mixture into deionized water for several times, no AgI formed when the water phase was tested with $\mathrm{AgNO}_{3}$, which showed that the generated LiI had been fully removed, and [PNOEG $^{+}$TFSI $^{-}$was obtained. Membrane fabrication is based on Huisgen 1,3-dipolar cycloaddition between $p$-xylyene diazide and $[\mathbf{P N}-\mathbf{O E G}]^{+}$TFSI $^{-}$and the membrane was cured to $150{ }^{\circ} \mathrm{C}$ to ensure the complete polymerization. Three different membranes were prepared by manipulate the ratio between PN

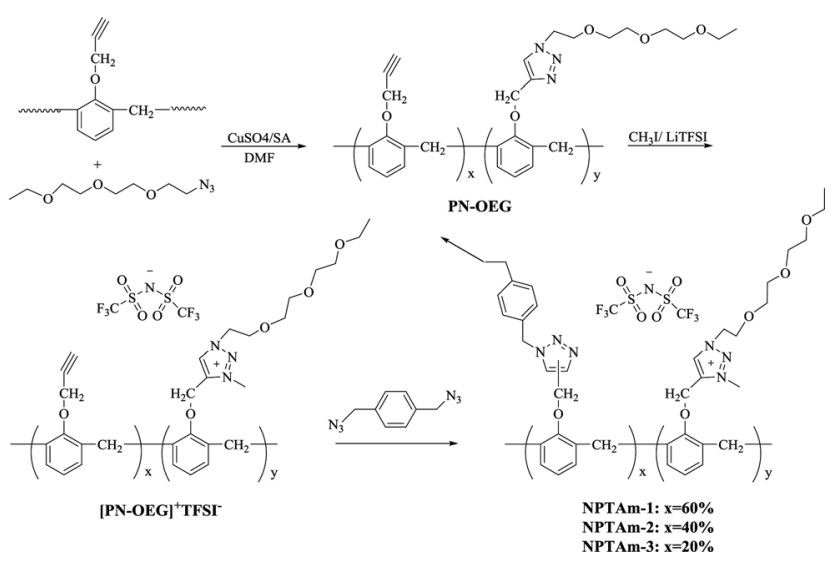

Fig. 1 Syntheses of the crosslinked NPTAm membranes and the selfstanding ability test. and OEG- $\mathrm{N}_{3}$ as $1: 0.4,1: 0.6$ and $1: 0.8$, and thus the number of side-chain 1,2,3-triazolium and OEG moieties together with the crosslinking density were easily changed. The obtained membranes were observed to be self-standing as shown in Fig. 1. NPTAm-3 membrane (thickness $150 \mu \mathrm{m}$, wide $0.7 \mathrm{~cm}$ ), as an example, could easily sustained an applied load of at least $20 \mathrm{~g}$, that is, tensile force of a minimum of $1.87 \times 10^{5} \mathrm{~Pa}$.

\section{Structural characterization}

Fig. 2 shows the ${ }^{1} \mathrm{H}$ NMR spectra of PN-OEG, [PN-OEG] ${ }^{+} \mathbf{I}^{-}$and $\left[\right.$ PN-OEG] ${ }^{+}$TFSI $^{-}$. For PN-OEG, the signals at 8.11-7.94 ppm assigned to 1,2,3-triazole ring confirm the success of CuAAC reaction. After alkylated by $\mathrm{CH}_{3} \mathrm{I}$, the triazole signals moves down to $9.01 \mathrm{ppm}$ in the spectra of [PN-OEG] $]^{+} \mathbf{I}^{-}$, clearly demonstrating the accomplishment of quaternization and the formation of 1,2,3triazolium. Also, the new signals appeared at $4.35 \mathrm{ppm}$ could be ascribed to the methyl protons connecting with the nitrogen atom of the 1,2,3-triazolium ring. After exchanging $\mathrm{I}^{-}$anions with $\mathrm{TFSI}^{-}$ anions, in the spectra of [PN-OEG] $]^{+}$TFSI $^{-}$, the chemical shift of 1,2,3-triazolium protons slightly shifted from $9.01 \mathrm{ppm}$ to $8.95 \mathrm{ppm}$ and the signal of methyl protons shifted down to $4.31 \mathrm{ppm}$, indicating quantitative anion-exchange reaction.

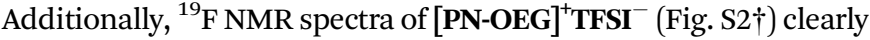
showed a single peak, which was further evidence for the completion of anion exchange reaction.

FTIR analysis was used to investigate the reaction between $p$ xylyene diazide and [PN-OEG] ${ }^{+}$TFSI $^{-}$(Fig. S3†). Compared to the spectrum of [PN-OEG] ${ }^{+}$TFSI $^{-}$, the red shift of the 1,2,3-triazole absorption peak from $3120 \mathrm{~cm}^{-1}$ to $3128 \mathrm{~cm}^{-1}$ and the
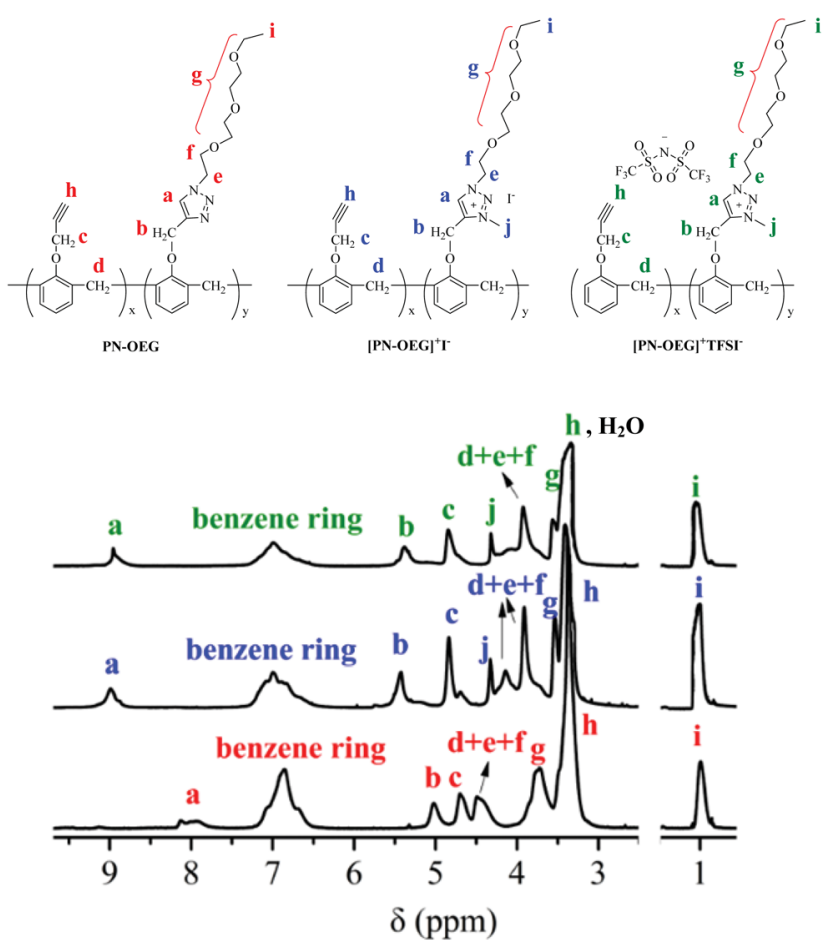

Fig. $2{ }^{1} \mathrm{H}$ NMR spectra $\left(25^{\circ} \mathrm{C}\right.$, DMSO- $\left.d_{6}\right)$ of PN-OEG, [PN-OEG] ${ }^{+} I^{-}$ and $[\mathrm{PN}-\mathrm{OEG}]^{+} \mathrm{TFSI}^{-}$. 
disappearance of the $-\mathrm{C} \equiv \mathrm{C}-$ group absorption peak at $2122 \mathrm{~cm}^{-1}$ are indicative of the formation of NPTAm-1 through the polymerization based on 1,3-dipolar cycloaddition reaction between the alkyne groups in $[\mathbf{P N}-\mathbf{O E G}]^{+} \mathbf{T F S I}^{-}$and the azido groups in $p$-xylyene diazide.

\section{Thermal properties of the NPTAm membranes}

Generally, ion transport in polyelectrolytes is related with segmental motion in the vicinity of conducting ions, and a low $T_{\mathrm{g}}$ promotes the transportation of ions. ${ }^{11,21}$ The thermal properties of the NPTAm membranes were investigated by DSC and TGA (Fig. 3, Table 1). All the samples exhibit a single transition corresponding to the glass transition temperature $\left(T_{\mathrm{g}}\right)$ values of $-1.0{ }^{\circ} \mathrm{C}$ for NPTAm- $1,-4.6{ }^{\circ} \mathrm{C}$ for NPTAm-2 and $-7.5{ }^{\circ} \mathrm{C}$ for NPTAm-3. NPTAm-3 showed the lowest $T_{\mathrm{g}}$, indicating the lowest crosslinking density and inversely most flexible oligo(ethylene glycol) side groups. It could be further confirmed from the DMA result (Fig. S4 $\dagger$ ) that NPTAm-3 exhibited the lowest storage
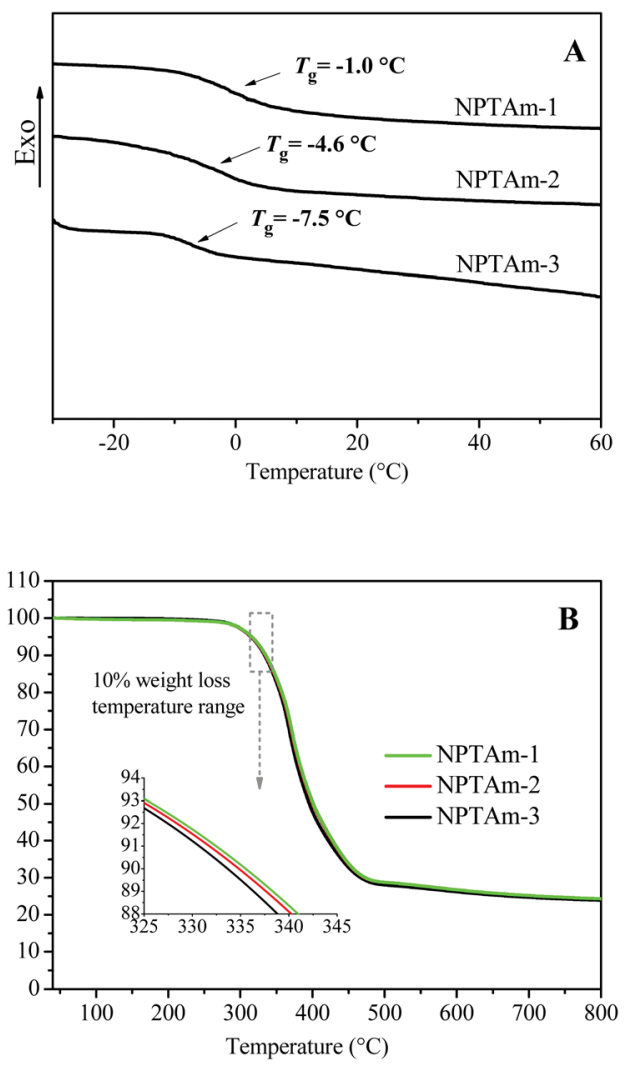

Fig. 3 (A) DSC, (B) TGA curves of the crosslinked NPTAm membranes. modulus in the rubbery state $\left(E^{\prime}=16.9 \mathrm{MPa}\right.$ and $5.2 \mathrm{MPa}$ at $25{ }^{\circ} \mathrm{C}$ for NPTAm- 1 and NPTAm-3, respectively). However, these NPTAm membranes showed remarkably high $T_{g}$ values as compared with previously reported crosslinked TPILs having TFSI $^{-}$counter-anions $\left(T_{\mathrm{g}}\right.$ ranges from -52 to $\left.-65{ }^{\circ} \mathrm{C}\right) .{ }^{9,16}$ The rigid benzene rings and 1,2,3-triazoles in the backbone along with the $\pi-\pi$ stacking and hydrogen bonding character of numerous 1,2,3-triazolium groups ${ }^{22}$ may account for the higher $T_{\mathrm{g}}$ values. TGA results indicate that all the membranes have good thermal stabilities above $330^{\circ} \mathrm{C}\left(T_{\mathrm{d} 10}\right)$, which are in the upper range of values previously reported TPILs $\left(145-371{ }^{\circ} \mathrm{C}\right) .{ }^{5}$

\section{Ionic conductivity of the NPTAm membranes}

The temperature dependence of the anhydrous ionic conductivity of these NPTAm membranes was investigated by BDS. As an example, Fig. 4A describes the frequency $(\omega)$ dependence of the conductivity $\left(\sigma^{\prime}\right)$ at temperature ranging from -30 to $110^{\circ} \mathrm{C}$ for NPTAm-3. A plateau in the $\sigma^{\prime}$ value between two characteristic frequency $\left(f_{\mathrm{E}}, f_{\mathrm{EP}}\right)$ could be observed for all membranes samples when the temperature was above $10{ }^{\circ} \mathrm{C}$ (Fig. S5 $\dagger$ ). This plateau corresponds to the direct current conductivity $\left(\sigma_{\mathrm{DC}}\right)$, which associates with the appearance of the ionic conduction character. Considering the correlation between the charge transport of the ionic species and the molecular mobility of the polymer chain, the evolution of $\sigma_{\mathrm{DC}}$ with reciprocal temperature for all NPTAm membranes follows a typical Vogel-FulcherTammann (VFT) dependence, and thus the experimental results fitted with the VFT eqn (3).

$$
\sigma_{\mathrm{DC}}=\sigma_{\infty} \times \exp \left(\frac{-B}{T-T_{0}}\right)
$$

where $\sigma_{\infty}$ is the ionic conductivity in the limit of high temperature, $B$ is the fitting parameter related to the activation energy of ionic conduction, and $T_{0}$ is the Vogel temperature. (Fig. 4B)

As shown in Table 1, NPTAm-3 showed the highest ionic conductivity $\left(\sigma_{\mathrm{DC}}\right.$ at $\left.30^{\circ} \mathrm{C}\right)$ of $5.1 \times 10^{-7} \mathrm{~S} \mathrm{~cm}^{-1}$ compared with NPTAm-1 $\left(2.8 \times 10^{-8} \mathrm{~S} \mathrm{~cm}^{-1}\right)$ and NPTAm-2 membranes $(7.9 \times$ $\left.10^{-8} \mathrm{~S} \mathrm{~cm}^{-1}\right)$. The enhanced ionic conductivity of NPTAm-3 could be attributed to the high dissociation and mobility of the maximum $\mathrm{TFSI}^{-}$anions promoted by the largest number of side-chain OEG as discussed above on $T_{\mathrm{g}} \mathrm{s}$. Except from the crosslinked polyether-based TPIL $\left(\sigma_{\mathrm{DC}}\right.$ up to $3.9 \times$ $\left.10^{-6} \mathrm{~S} \mathrm{~cm}^{-1}\right),{ }^{9}$ the ionic conductivity of NPTAm-3 is slightly high for a reported crosslinked TPILs ( $\sigma_{\mathrm{DC}}$ ranges from $2.2 \times 10^{-11}$ to $\left.2.0 \times 10^{-7} \mathrm{~S} \mathrm{~cm}^{-1}\right),{ }^{14,16,23}$ clearly demonstrating the structural advantage of introducing the conductive ions in the side groups spaced by flexible ether groups with $\mathrm{TFSI}^{-}$as counter-anions.

Table 1 Thermal and ion-conducting properties of the NPTAm membranes

\begin{tabular}{llllllll}
\hline Entry & $T_{\mathrm{g}}{ }^{a}\left({ }^{\circ} \mathrm{C}\right)$ & $T_{\mathrm{d} 10}{ }^{b}\left({ }^{\circ} \mathrm{C}\right)$ & $E^{\prime c}(\mathrm{MPa})$ & $\sigma_{\mathrm{DC}} \mathrm{at}^{d} 30^{\circ} \mathrm{C}\left(\mathrm{S} \mathrm{cm}^{-1}\right)$ & $B^{d}(\mathrm{~K})$ & $T_{0}{ }^{d}(\mathrm{~K})$ & $\sigma_{\infty}{ }^{d}\left(\mathrm{~S} \mathrm{~cm}{ }^{-1}\right)$ \\
\hline NPTAm-1 & -1.0 & 336 & 16.9 & $2.8 \times 10^{-8}$ & 1400 & 212 \\
NPTAm-2 & -4.6 & 335 & - & $7.9 \times 10^{-8}$ & 1389 & 210 \\
NPTAm-3 & -7.5 & 333 & 5.2 & $5.1 \times 10^{-7}$ & 1349 & 213
\end{tabular}

${ }^{a}$ Obtained from DSC. ${ }^{b}$ Obtained from TGA. ${ }^{c}$ Obtained from DMA. ${ }^{d}$ Obtained from BDS. 

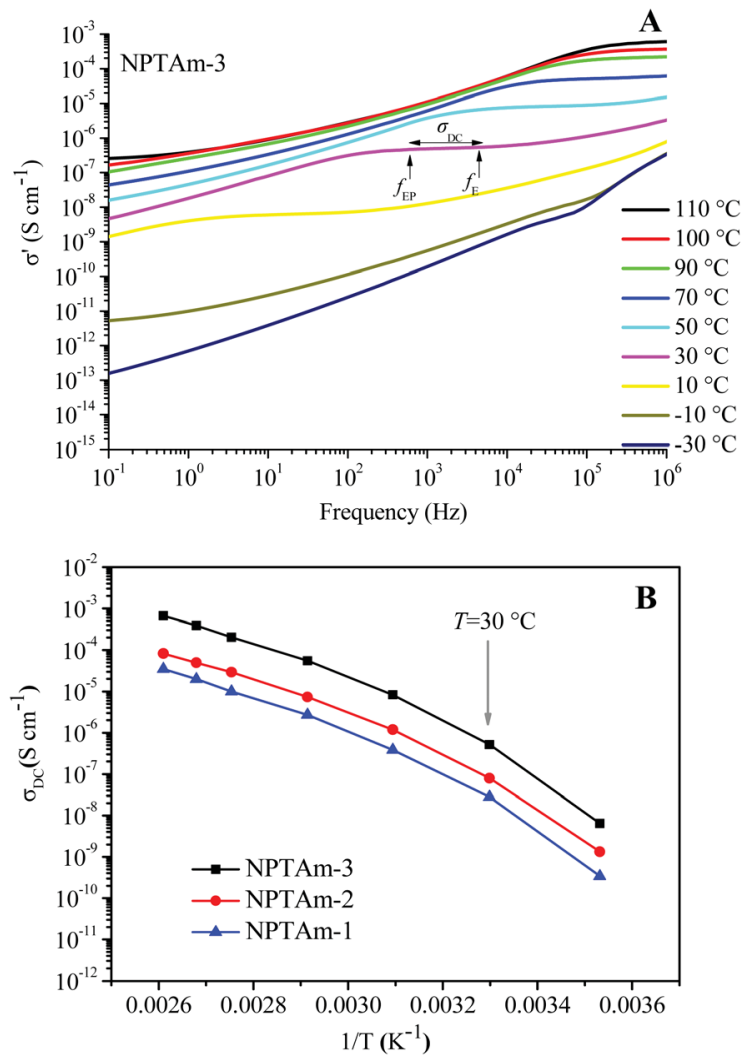

Fig. 4 (A) Conductivity versus frequency for the crosslinked NPTAm membranes. (B) Direct current conductivity $\left(\sigma_{\mathrm{DC}}\right)$ versus inverse temperature for the NPTAm membranes. The solid lines represent the best VFT fit of experimental data using eqn (3).

Table 2 Gas transport properties of the NPTAm membranes ${ }^{a}$

\begin{tabular}{lccl}
\hline Entry & $P_{\mathrm{CO}_{2}}$ (barrer) & $P_{\mathrm{N}_{2}}$ (barrer) & $\mathrm{CO}_{2} / \mathrm{N}_{2}$ selectivity \\
\hline NPTAm-1 & 264.7 & 14.4 & 18.4 \\
NPTAm-3 & 434.5 & 35.1 & 12.3 \\
${ }^{a} 1$ barrer $=10^{-10} \mathrm{~cm}^{3}(\mathrm{STP}) \mathrm{cm}\left(\mathrm{cm}^{2} \mathrm{~s} \mathrm{cmHg}\right)^{-1}$. &
\end{tabular}

\section{Gas separation of the NPTAm membranes}

The gas separation performances of the NPTAm membranes are summarized in Table 2. The membranes show $\mathrm{CO}_{2}$ permeability of 264.7-434.5 barrer and $\mathrm{CO}_{2} / \mathrm{N}_{2}$ selectivity of 18.4-12.3. Compared to NPTAm-1, NPTAm-3 had higher $\mathrm{CO}_{2}$ permeability but decreased $\mathrm{CO}_{2} / \mathrm{N}_{2}$ selectivity, following a traditional tradeoff. Fig. 5 shows the comparison of the separation performances of this work with the reported data of other crosslinked TPILs membranes. ${ }^{9}$ The $\mathrm{CO}_{2}$ permeability is relatively enhanced. Firstly, there were higher density of side-chain OEG and 1,2,3-triazolium moieties inside the NPTAm membranes. The numerous OEG provided plentiful polar ether groups, which are efficient $\mathrm{CO}_{2}$-philic units and could efficiently improve $\mathrm{CO}_{2}$ affinity. Secondly, the presence of aromatic groups in the backbone significantly improves the $\mathrm{CO}_{2}$ uptake. ${ }^{6}$ Although both work could not reach Robeson's upper bound,

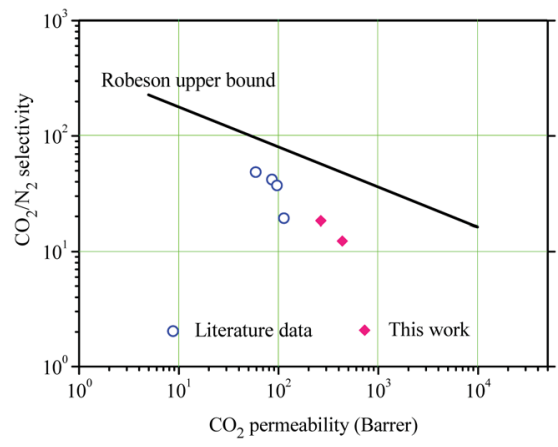

Fig. 5 Comparison of the gas transport properties of the membranes with the literature data. ${ }^{9,24}$

they convince crosslinked TPILs membranes as promising separation materials and optimization of their structure through Click chemistry (1,3-dipolar cycloaddition reaction) will endow them further enhancement in both the permeability and selectivity.

\section{Conclusion}

Crosslinked poly(1,2,3-triazolium)s membranes with 1,2,3-triazolium in side chain spaced by oligo(ethylene glycol) were prepared through "Click" chemistry (Huisgen 1,3-dipolar cycloaddition reaction). These self-standing membranes show good thermal properties with $T_{\mathrm{g}} \mathrm{s}$ ranging from -1.0 to $-7.5{ }^{\circ} \mathrm{C}$ and $T_{\mathrm{d} 10}$ above $330{ }^{\circ} \mathrm{C}$. These membranes have good ionic conductivity with $\sigma_{\mathrm{DC}}$ at $30{ }^{\circ} \mathrm{C}$ up to $5.1 \times 10^{-7} \mathrm{~S} \mathrm{~cm}^{-1}$. The structure of rigid benzene ring in the backbone with 1,2,3-triazolium spaced by flexible OEG as side groups contribute to enhanced $\mathrm{CO}_{2}$ permeation, up to 434.5 barrer at 4 atm pressure.

\section{Conflicts of interest}

There are no conflicts to declare.

\section{Acknowledgements}

This work was supported by the Fundamental Research Funds for the Central Universities (No. 222201717001).

\section{References}

1 W. Qian, J. Texter and F. Yan, Chem. Soc. Rev., 2017, 46, 11241159.

2 Z. Dai, R. D. Noble, D. L. Gin, X. Zhang and L. Deng, J. Membr. Sci., 2016, 497, 1-20.

3 C. Zhang, W. Zhang, H. Gao, Y. Bai, Y. Sun and Y. Chen, J. Membr. Sci., 2017, 528, 72-81.

4 S. M. Morozova, A. S. Shaplov, E. I. Lozinskaya, D. Mecerreyes, H. Sardon, S. Zulfiqar, F. Suárez-García and Y. S. Vygodskii, Macromolecules, 2017, 50, 2814-2824.

5 A. Jourdain, I. Antoniuk, A. Serghei, E. Espuche and E. Drockenmuller, Polym. Chem., 2017, 8, 5148-5156. 
6 S. Zulfiqar, M. I. Sarwar and D. Mecerreyes, Polym. Chem., 2015, 6, 6435-6451.

7 S. C. Kumbharkar, R. S. Bhavsar and U. K. Kharul, RSC Adv., 2014, 4, 4500-4503.

8 J. Yang, J. Zheng, J. Zhang, L. Sun, F. Chen, P. Fan and M. Zhong, RSC Adv., 2015, 5, 32853-32861.

9 X. Zhou, M. M. Obadia, S. R. Venna, E. A. Roth, A. Serghei, D. R. Luebke, C. Myers, Z. Chang, R. Enick, E. Drockenmuller and H. B. Nulwala, Eur. Polym. J., 2016, 84, 65-76.

10 B. P. Mudraboyina, M. M. Obadia, I. Allaoua, R. Sood, A. Serghei and E. Drockenmuller, Chem. Mater., 2014, 26, 1720-1726.

11 J. Wu, J. Chen, J. Wang, X. Liao, M. Xie and R. Sun, Polym. Chem., 2016, 7, 633-642.

12 G. Colliat-Dangus, M. M. Obadia, Y. S. Vygodskii, A. Serghei, A. S. Shaplov and E. Drockenmuller, Polym. Chem., 2015, 6, 4299-4308.

13 M. M. Obadia, G. Colliat-Dangus, A. Debuigne, A. Serghei, C. Detrembleur and E. Drockenmuller, Chem. Commun., 2015, 51, 3332-3335.

14 M. M. Obadia, B. P. Mudraboyina, A. Serghei, D. Montarnal and E. Drockenmuller, J. Am. Chem. Soc., 2015, 137, 60786083.

15 M. M. Obadia, A. Jourdain, P. Cassagnau, D. Montarnal and E. Drockenmuller, Adv. Funct. Mater., 2017, 27, 1703258.
16 T. K. Ly Nguyen, M. M. Obadia, A. Serghei, S. Livi, J. DuchetRumeau and E. Drockenmuller, Macromol. Rapid Commun., 2016, 37, 1168-1174.

17 S. Ciampi, M. James, G. Le Saux, K. Gaus and J. Justin Gooding, J. Am. Chem. Soc., 2012, 134, 844-847.

18 L. Ye, L. Wan and F. Huang, High Perform. Polym., 2018, 30, 109-115.

19 L. Wan, Y. Luo, L. Xue, J. Tian, Y. Hu, H. Qi, X. Shen, F. Huang, L. Du and X. Chen, J. Appl. Polym. Sci., 2007, 104, 1038-1042.

20 P. Bernardo, F. Bazzarelli, F. Tasselli, G. Clarizia, C. R. Mason, L. Maynard-Atem, P. M. Budd, M. Lanč, K. Pilnáček, O. Vopička, K. Friess, D. Fritsch, Y. P. Yampolskii, V. Shantarovich and J. C. Jansen, Polymer, 2017, 113, 283-294.

21 B. P. Mudraboyina, M. M. Obadia, I. Abdelhedi-Miladi, I. Allaoua and E. Drockenmuller, Eur. Polym. J., 2015, 62, 331-337.

22 F. Zapata, L. Gonzalez, A. Caballero, I. Alkorta, J. Elguero and P. Molina, Chem.-Eur. J., 2015, 21, 9797-9808.

23 I. Abdelhedi-Miladi, D. Montarnal, M. M. Obadia, H. Ben Romdhane and E. Drockenmuller, ACS Macro Lett., 2014, 3, 1187-1190.

24 L. M. Robeson, J. Membr. Sci., 2008, 320, 390-400. 